\title{
COMPARAÇÃO DA QUALIDADE FÍSICA DE OVOS DO TIPO CAIPIRA E DE GRANJA NO INTERIOR DE MINAS GERAIS
}

\author{
D. B. S. FERREIRA ${ }^{1}$, E. A. FERNANDES ${ }^{2}$, A. G. L. SAAR ${ }^{2}$, A. G. S. MOURA ${ }^{1}$ e \\ M. LIMA ${ }^{1}$ \\ ${ }^{1}$ Universidade Federal de Uberlândia, Faculdade de Engenharia Química \\ ${ }^{2}$ Universidade Federal de Uberlândia, Faculdade de Medicina Veterinária \\ E-mail para contato: marieli@ufu.br
}

\begin{abstract}
RESUMO - O objetivo do trabalho foi comparar a qualidade física de ovos do tipo caipira e de granja produzidos em Patos de Minas e Uberlândia - MG, durante o armazenamento de 11 dias a temperatura ambiente $\left(25^{\circ} \mathrm{C}\right)$. Para tal, foram realizadas a quantificação de massa total, massa da casca, densidade, umidade e altura e diâmetro do albúmen e da gema e unidade Haugh. A perda de massa e a perda de umidade (2\%) não foi significativa entre os ovos e durante o armazenamento. Houve redução da densidade, da altura da gema e do albúmen, além da unidade Haugh para todas as amostras, acompanhadas do aumento do diâmetro de albúmen e da gema durante os 11 dias, o que evidenciam as alterações decorrentes do envelhecimento do produto. O tipo de ovos (granja ou caipira) não influenciou no peso total, na densidade e na altura do albúmen. No entanto, houve diferença na unidade Haugh aos 11 dias de armazenamento, o que sugere que os ovos de granja sofreram degradação mais acentuada. O diâmetro e a altura da gema foram maiores nos ovos tipo caipira, enquanto a umidade, o peso da casca, o diâmetro e peso do albúmen foram superiores nos ovos de granja. As principais diferenças encontradas nas características físicas dos ovos de granja e do tipo caipira são relativas às proporções de gema e de albúmen dos mesmos. O desempenho de todas as amostras durante o armazenamento foi semelhante, o que pode evidenciar que a degradação dos ovos sofre maior influência das condições de armazenagem do que em relação à origem dos ovos.
\end{abstract}

\section{INTRODUÇÃO}

O ovo é um alimento completo e equilibrado em nutrientes, constituindo uma fonte de proteína de baixo valor econômico, o que o torna viável para a alimentação de famílias de baixa renda. Além do consumo direto, é matéria-prima de uma variedade de produtos, como as massas alimentícias, bolos, biscoitos e outros produtos de panificação e doces em geral (Machado, 2014).

Existem dois tipos de ovos de galinhas comercializados no mercado: ovos de granja e ovos caipiras. No entanto, para que a utilização do ovo caipira pelo consumidor seja viável, é preciso que este apresente os mesmos requisitos de qualidade exigidos para os ovos de granja. $\mathrm{O}$ fato de não possuir leis que regulamentem o comércio de ovos caipiras dificulta a 
padronização desse produto, pois não existem parâmetros para serem comparados; cada agricultor cria suas aves de uma maneira, principalmente com as mais variadas formas de alimentação; existem muitos tipos de raças de galinhas caipiras; não há garantia de armazenagem correta desses ovos; dentre outros fatores (Sagrilo, 2007).

Os ovos do tipo caipira possuem produção realizada por pequenos produtores e geralmente, para reprodução de novas aves, consumo próprio ou ainda para comercialização em feiras e pequenos estabelecimentos comerciais. São muito apreciados pela população local, e são cercados por muitos mitos, como atribuir a origem "caipira" a um produto "natural", com maiores benefícios ou mesmo características mais atrativas do que as encontradas nos ovos de granja.

Essas diferenças encontradas nos ovos, podem ser ainda mais acentuadas quando se compara ovos caipira com ovos de granja. Isso se deve ao fato de que os modos como são produzidos serem tão distintos, principalmente o uso (ou não) das Boas Práticas Agrícolas e o manejo, que, no caso de ovos caipira, são comercializados pelos próprios produtores, na maioria das vezes, não seguem nenhuma prática de higiene proposta pela Legislação, tornando o ovo um alimento duvidoso.

Alguns estudos realizados sobre a qualidade de ovos como alimento humano encontrados na literatura referenciam apenas ovos de granja e não comparam as características físicas entre os ovos de granja e os ovos caipira. Frente ao exposto, o objetivo deste trabalho foi comparar a qualidade física de ovos de granja e de ovos caipira provenientes de Patos de Minas e Uberlândia, localizadas no Triângulo Mineiro.

\section{MATERIAIS E MÉTODOS}

Foram utilizados o total de 90 ovos, sendo 45 ovos caipiras obtidos de pequenos produtores em algumas propriedades rurais na região de Patos de Minas e 45 ovos de granja fornecidos pela Fazenda Experimental da Universidade Federal de Uberlândia - UFU, localizada na cidade de Uberlândia - MG.

\subsection{Análises físico-químicas}

As amostras foram avaliadas em pools de 15 ovos de cada origem (granja e caipira) com relação a massa total, a massa da casca, a densidade e a unidade Haugh. A gema e o albúmen foram separados para avaliar o diâmetro, a altura, a massa e a umidade. Todas as amostras foram armazenadas a temperatura ambiente $\left(\approx 25^{\circ} \mathrm{C}\right)$ e avaliadas aos 1,6 , e 11 dias.

\subsection{Análise Estatística}

A diferença significativa entre o tipo dos ovos e as mudanças nos parâmetros com o tempo de armazenamento foram avaliadas através de ANOVA. A comparação de médias para os fatores que apresentaram diferença significativa $(\mathrm{p}<0,05)$ foi realizada através do teste de T. Para a realização da análise de variância e teste T foi utilizado o software Assistat. 


\section{RESULTADOS E DISCUSSÃO}

A Tabela 1 apresenta os valores de massa total e da massa da casca dos ovos do tipo caipira e de granja durante o armazenamento sob 11 dias. A massa total dos ovos apresentou redução média de $2 \mathrm{~g}$ no decorrer no período. No entanto, esse declínio não foi significativo durante o armazenamento e não houve diferença de massa total entre os ovos caipiras e dos ovos de granja $(\mathrm{p}<0,05)$. O trabalho de Garcia (2010) menciona que a perda de massa em ovos armazenados está associada à migração de umidade devido a porosidade da casca, que permite a troca de vapor de água e gases, além da influência da temperatura de armazenamento, onde sob temperaturas mais altas, a perda de massa total tende a ser mais acentuada.

Tabela 1 - Média da massa total e da massa da casca (g) de ovos do tipo caipira e de granja durante o armazenamento a $25{ }^{\circ} \mathrm{C}$.

\begin{tabular}{|c|c|c|c|c|}
\hline \multirow{2}{*}{$\begin{array}{c}\text { Tempo } \\
(\text { dias }\end{array}$} & \multicolumn{2}{|c|}{ Massa Total $(\mathrm{g})$} & \multicolumn{2}{c|}{ Massa da casca $(\mathrm{g})$} \\
\cline { 2 - 5 } & Caipira & Granja & Caipira & Granja \\
\hline \hline 1 & $57,11 \pm 14,90^{\mathrm{aA}}$ & $59,22 \pm 14,49^{\mathrm{aA}}$ & $6,48 \pm 1,53^{\mathrm{aA}}$ & $7,37 \pm 1,56^{\mathrm{bA}}$ \\
\hline 6 & $54,80 \pm 5,18^{\mathrm{aA}}$ & $58,12 \pm 13,71^{\mathrm{aA}}$ & $6,19 \pm 0,63^{\mathrm{aA}}$ & $7,29 \pm 1,75^{\mathrm{bA}}$ \\
\hline 11 & $56,33 \pm 6,15^{\mathrm{aA}}$ & $57,59 \pm 13,79^{\mathrm{aA}}$ & $6,49 \pm 1,47^{\mathrm{aA}}$ & $7,27 \pm 1,52^{\mathrm{bA}}$ \\
\hline
\end{tabular}

Letras minúsculas entre colunas: diferem quanto à origem dos ovos. Letras maiúsculas entre linhas: diferem quanto ao período de armazenamento. $\mathrm{p}<0,05$.

A massa da casca das amostras não apresentou alterações com o armazenamento. No entanto, foi observado que houve diferença significativa $(\mathrm{p}<0,05)$ de acordo com o tipo de ovos, onde a casca do ovo caipira apresentou massa maior do que a casca de ovos de granja. Isto pode estar associado à raça da poedeira, idade, alimentação, entre outros fatores, que influenciam na secreção de carbonato de cálcio e no processo de formação da casca (Figueiredo et al., 2012).

A Tabela 2 apresenta os valores de densidade $\left(\mathrm{g} / \mathrm{cm}^{3}\right)$ e de unidade Haugh dos ovos do tipo caipira e de granja durante o armazenamento sob 11 dias. Após o primeiro dia de postura, os ovos de granja mostraram-se mais densos que os ovos tipo caipira de forma significativa $(\mathrm{p}<0,05)$. No entanto, após o sexto dia, a densidade foi semelhante para todas as amostras, o que evidencia que a diminuição da densidade observada no decorrer do armazenamento não está associada com o tipo de ovos, mas de acordo com o trabalho de Rodrigues (2011), que destaca que a alteração do tamanho da câmara de ar aumenta devido às perdas de água e de dióxido de carbono através da casca durante o armazenamento, sendo um indicativo de qualidade do ovo, onde redução da densidade está associada à perda de massa e de frescor deste produto.

A Unidade Haugh (UH) é muito utilizada nos EUA pela United States Department of Agriculture (USDA), através do Programa de Controle da Qualidade dos Ovos para Consumo. De acordo com os valores de Unidade Haugh, recomenda que ovos considerados de excelente qualidade (AA) devem apresentar valores de UH superiores a 72; ovos de qualidade alta (A), entre 55 a $72 \mathrm{UH}$; ovos de qualidade média (B), superiores a $30 \mathrm{UH}$; e, finalmente, ovos de baixa qualidade, com valores de UH inferiores a 30 (BARBOSA, 2008). De acordo com esses preceitos, houve perda na qualidade, visto que os ovos de ambos os tipos passaram de excelente qualidade (com 1 dia de armazenamento) com médias entre 88 e 89 UH para ovos de qualidade média com apenas 11 dias de armazenamento com valores de UH de 45 a 52. 
Tabela 2 - Média da densidade total $\left(\mathrm{g} / \mathrm{cm}^{3}\right)$ e da Unidade Haugh de ovos do tipo caipira e de granja durante o armazenamento a $25^{\circ} \mathrm{C}$.

\begin{tabular}{|c|c|c|c|c|}
\hline \multirow{2}{*}{$\begin{array}{c}\text { Tempo } \\
\text { (dias })\end{array}$} & \multicolumn{2}{|c|}{ Densidade $\left(\mathrm{g} / \mathrm{cm}^{3}\right)$} & \multicolumn{2}{c|}{ Unidade Haugh } \\
\cline { 2 - 5 } & Caipira & Granja & Caipira & Granja \\
\hline \hline 1 & $1,08 \pm 0,02^{\mathrm{aA}}$ & $1,09 \pm 0,27^{\mathrm{bA}}$ & $89,05 \pm 23,00^{\mathrm{aA}}$ & $88,74 \pm 18,52^{\mathrm{aA}}$ \\
\hline 6 & $1,07 \pm 1,23^{\mathrm{aB}}$ & $1,07 \pm 0,04^{\mathrm{aB}}$ & $65,03 \pm 18,34^{\mathrm{aA}}$ & $60,16 \pm 11,54^{\mathrm{aA}}$ \\
\hline 11 & $1,06 \pm 2,48^{\mathrm{aC}}$ & $1,06 \pm 0,36^{\mathrm{aC}}$ & $52,62 \pm 15,06^{\mathrm{aB}}$ & $45,88 \pm 9,47^{\mathrm{bB}}$ \\
\hline
\end{tabular}

Letras minúsculas entre colunas: diferem quanto à origem dos ovos. Letras maiúsculas entre linhas: diferem quanto ao período de armazenamento. $\mathrm{p}<0,05$.

O valor da UH reduziu ( $\mathrm{p}<0,05$ ) com o tempo, porém houve diferença significativa entre os tipos de ovos apenas no $11^{\circ}$ dia de armazenamento, o que evidencia que os ovos tipo caipira mantiveram melhor a qualidade do que os ovos de granja.

A Tabela 3 apresenta o comportamento do diâmetro e da altura da gema e do albúmen dos ovos do tipo caipira e de granja durante o armazenamento sob 11 dias. O diâmetro da gema e do albúmen de todas as amostras apresentaram aumento significativo $(\mathrm{p}<0,05)$ durante $\mathrm{o}$ armazenamento. Este tipo de comportamento foi semelhante ao encontrado por Salvador (2011), que descreve que no armazenamento em faixas mais altas, como a temperatura ambiente, provoca o aumento da permeabilidade da membrana vitelínica, facilitando a entrada de parte da água do albúmen para a gema. Assim, a mesma perde a sua forma original que é esférica, tornandose elíptica, aumentando o seu diâmetro e a possibilidade de rompimento da membrana durante a manipulação do ovo.

Tabela 3 - Média do diâmetro $(\mathrm{mm})$ e da altura $(\mathrm{mm})$ da gema e do albúmen dos ovos do tipo caipira e de granja durante o armazenamento a $25^{\circ} \mathrm{C}$.

\begin{tabular}{|c|c|c|c|c|}
\hline \multirow{2}{*}{$\begin{array}{c}\text { Tempo } \\
\text { (dias) }\end{array}$} & \multicolumn{2}{|c|}{ Diâmetro da gema $(\mathrm{mm})$} & \multicolumn{2}{c|}{ Diâmetro do albúmen $(\mathrm{mm})$} \\
\cline { 2 - 5 } & Caipira & Granja & Caipira & Granja \\
\hline 1 & $44,92 \pm 11,24^{\mathrm{aA}}$ & $42,31 \pm 8,00^{\mathrm{bA}}$ & $89,94 \pm 23,14^{\mathrm{aA}}$ & $92,43 \pm 18,70^{\mathrm{aA}}$ \\
\hline 6 & $42,84 \pm 9,44^{\mathrm{aB}}$ & $42,08 \pm 8,35^{\mathrm{aB}}$ & $104,55 \pm 26,81^{\mathrm{aB}}$ & $119,61 \pm 25,96^{\mathrm{bB}}$ \\
\hline 11 & $46,78 \pm 9,26^{\mathrm{aC}}$ & $46,09 \pm 9,46^{\mathrm{aC}}$ & $117,28 \pm 31,21^{\mathrm{aC}}$ & $137,32 \pm 29,30^{\mathrm{bC}}$ \\
\hline $\begin{array}{c}\text { Tempo } \\
(\text { dias})\end{array}$ & \multicolumn{2}{|c|}{ Altura da gema $(\mathrm{mm})$} & \multicolumn{2}{|c|}{ Altura do albúmen } \\
\cline { 2 - 5 } & Caipira & Granja & Caipira & Granja \\
\hline 1 & $19,13 \pm 4,83^{\mathrm{aA}}$ & $18,38 \pm 3,68^{\mathrm{aA}}$ & $7,88 \pm 2,15^{\mathrm{aA}}$ & $7,98 \pm 2,02^{\mathrm{aa}}$ \\
\hline 6 & $14,59 \pm 2,57^{\mathrm{aB}}$ & $13,79 \pm 2,96^{\mathrm{bB}}$ & $4,50 \pm 1,10^{\mathrm{aB}}$ & $4,09 \pm 0,85^{\mathrm{aB}}$ \\
\hline 11 & $13,64 \pm 1,30^{\mathrm{aB}}$ & $12,23 \pm 2,96^{\mathrm{bC}}$ & $3,44 \pm 2,09^{\mathrm{aC}}$ & $2,93 \pm 0,42^{\mathrm{aC}}$ \\
\hline
\end{tabular}

Letras minúsculas entre colunas: diferem quanto à origem dos ovos. Letras maiúsculas entre linhas: diferem quanto ao período de armazenamento. $\mathrm{p}<0,05$.

O comportamento do diâmetro da gema e do albúmen com relação ao tipo de ovos foi distinto. Os ovos caipiras apresentaram diâmetro significativamente maior do que os ovos de granja apenas no primeiro dia após a postura, e no decorrer do armazenamento, o comportamento foi semelhante para todas as amostras. Para o albúmen, não houve diferença significativa do diâmetro para ovos caipira e de granja no primeiro dia. Em contrapartida, houve diferença significativa para ovos com 6 e 11 dias de armazenamento, evidenciando que o albúmen dos ovos de granja sofreu mais alterações que os ovos caipiras. 
A altura da gema de ovos caipiras foi maior do que de ovos de granja. Houve diferença significativa $(\mathrm{p}<0,05)$ a partir do sexto dia até o final do armazenamento. A altura do albúmen, no entanto, apresentou o mesmo comportamento para todos os ovos ( $p>0,05)$. Ao contrário do diâmetro, a altura média das gemas e do albúmen diminuiu, no decorrer do armazenamento, independentemente do tipo de ovos. Ou seja, houve um achatamento da gema e do albúmen devido às mesmas alterações fisiológicas atribuídas ao comportamento do diâmetro, mencionado anteriormente (Salvador, 2011).

A Tabela 4 apresenta a média da massa (g) e da umidade (\%) da gema e do albúmen dos ovos do tipo caipira e de granja durante o armazenamento a $25{ }^{\circ} \mathrm{C}$. Houve diferença significativa $(\mathrm{p}<0,05)$ entre o tipo de ovos, onde a massa da gema de ovos caipira foi maior do que nos ovos de granja, resultado oposto do encontrado para a massa do albúmen, que foi maior nos ovos de granja. Esse pode ser um dos fatores pelos quais os consumidores preferem usar ovos tipo caipira na confecção de receitas onde o interesse pela gema é maior, devido à sua maior proporção no ovo. Essas diferenças podem ser atribuídas à raça da galinha poedeira.

Tabela 4 - Média da massa (g) e da umidade (\%) da gema e do albúmen dos ovos do tipo caipira e de granja durante o armazenamento a $25^{\circ} \mathrm{C}$.

\begin{tabular}{|c|c|c|c|c|}
\hline \multirow{2}{*}{$\begin{array}{c}\text { Tempo } \\
\text { (dias) }\end{array}$} & \multicolumn{2}{|c|}{ Massa da gema $(\mathrm{g})$} & \multicolumn{2}{c|}{ Massa do albúmen $(\mathrm{g})$} \\
\hline & Caipira & Granja & Caipira & Granja \\
\hline 1 & $17,06 \pm 4,53^{\mathrm{aA}}$ & $15,53 \pm 3,07^{\mathrm{bA}}$ & $31,66 \pm 8,43^{\mathrm{aA}}$ & $34,49 \pm 7,53^{\mathrm{bA}}$ \\
\hline 6 & $18,33 \pm 4,45^{\mathrm{aA}}$ & $15,74 \pm 3,08^{\mathrm{bA}}$ & $28,27 \pm 6,49^{\mathrm{aB}}$ & $33,04 \pm 7,07^{\mathrm{bB}}$ \\
\hline 11 & $18,58 \pm 4,03^{\mathrm{aA}}$ & $16,12 \pm 3,34^{\mathrm{bA}}$ & $28,70 \pm 5,59^{\mathrm{aB}}$ & $31,73 \pm 7,59^{\mathrm{bB}}$ \\
\hline $\begin{array}{c}\text { Tempo } \\
\text { (dias) }\end{array}$ & \multicolumn{2}{|c|}{ Umidade da gema $(\%)$} & \multicolumn{2}{c|}{ Umidade do albúmen $(\%)$} \\
\cline { 2 - 5 } & Caipira & Granja & Caipira & Granja \\
\hline 1 & $44,82 \pm 0,50^{\mathrm{aA}}$ & $48,85 \pm 0,44^{\mathrm{aB}}$ & $86,50 \pm 0,26^{\mathrm{aA}}$ & $87,82 \pm 0,37^{\mathrm{bA}}$ \\
\hline 6 & $50,95 \pm 3,16^{\mathrm{aB}}$ & $51,95 \pm 0,35^{\mathrm{bA}}$ & $86,57 \pm 0,90^{\mathrm{aA}}$ & $87,36 \pm 0,51^{\mathrm{aA}}$ \\
\hline 11 & $51,42 \pm 2,21^{\mathrm{aB}}$ & $53,23 \pm 0,87^{\mathrm{aC}}$ & $86,11 \pm 0,52^{\mathrm{aA}}$ & $86,40 \pm 0,79^{\mathrm{aB}}$ \\
\hline
\end{tabular}

Letras minúsculas entre colunas: diferem quanto à origem dos ovos. Letras maiúsculas entre linhas: diferem quanto ao período de armazenamento. $\mathrm{p}<0,05$.

O teor de umidade na gema $(\approx 50 \%)$ foi inferior ao do albúmen $(\approx 87 \%)$. A umidade da gema foi maior em ovos de granja do que em ovos caipira e houve um aumento desse parâmetro para todas as amostras no decorrer do armazenamento. Salvador (2011) explica que durante o período de estocagem, ocorrem diversas reações físicas e químicas dentro do ovo, levando a degradação da estrutura da proteína presente na albumina espessa, sendo que temperaturas mais elevadas aceleram ainda mais essas reações. O produto das mesmas é a liberação de água ligada a grandes moléculas de proteína, aumentando a porcentagem de água no albúmen que passam para a gema por osmose. Em relação ao albúmen não foram evidenciadas a influência do tipo de ovos ou do armazenamento sobre a umidade. Isto pode ter sido influenciado pelas condições do ambiente de armazenamento.

\section{CONCLUSÃO}

As principais diferenças observadas entre os ovos, independente da origem foram o tamanho, o aspecto da casca e a massa, que podem ser atribuídas à forma de criação e manejo, o que pode ter contribuído no perfil dos resultados obtidos. A qualidade física dos ovos tipo 
caipira e de granja foi afetada pelo período de armazenamento. Isso foi observado principalmente através da redução dos valores de unidade Haugh, que é a principal ferramenta para determinação da qualidade de ovos comerciais. Os ovos caipiras conservaram mais a qualidade, pois obtiveram maiores valores de Unidade Haugh após 11 dias de postura, quando comparados aos ovos de granja. O diâmetro e a altura da gema foram maiores nos ovos tipo caipira, enquanto a umidade, o peso da casca, o diâmetro e peso do albúmen foram superiores nos ovos de granja. As principais diferenças encontradas nas características físicas dos ovos de granja e do tipo caipira são relativas às proporções de gema e de albúmen dos mesmos. $\mathrm{O}$ desempenho de todas as amostras durante o armazenamento foi semelhante, o que pode evidenciar que a degradação dos ovos sofre maior influência das condições de armazenagem do que em relação à origem dos ovos. Porém, em alguns aspectos, ovos provenientes de poedeiras do tipo caipira conservaram mais a qualidade em temperatura ambiente do que os ovos de poedeiras de granja em temperatura ambiente, podendo considerar então que ovos caipiras são de melhor qualidade.

\section{REFERÊNCIAS}

BARBOSA, N. A. A.; SAKOMURA, N. K.; MENDONÇA, M. O.; FREITAS, E. R. FERNANDES, J. B. K. Qualidade de ovos comerciais provenientes de poedeiras comerciais armazenados sob diferentes tempos e condições de ambientes. ARS VETERINARIA. Jaboticabal - SP, v.24, n.2, 127-133, 2008.

FIGUEIREDO, T.C.; CANÇADO, S.V.; VIEGAS, R.P.; RÊGO, I.O.P.; LARA, L.J.C., SOUZA, M.R.; BAIÃO, N.C. Qualidade de ovos comerciais submetidos a diferentes condições de armazenamento. Arquivo Brasileiro de Medicina Veterinária e Zootecnia. v.63, n.3, p.712-720, 2011.

GARCIA, E. R. M.; ORLANDI, C. C. B.; OLIVEIRA, C. A. L.; CRUZ, F. K.; SANTOS, T. M. B.; OTUTUMI, L. K. Qualidade de ovos de poedeiras semipesadas armazenados em diferentes temperaturas e períodos de estocagem. Revista Brasileira de Saúde e Produção Animal. Aquadauana - MS. v.11, n.2, p. 505-518, abr/jun, 2010.

RODRIGUES, L. S. Desempenho e qualidade de ovos de galinhas poedeiras de uma granja em região de clima tropical. 2011. 40 p. Trabalho de conclusão de curso (Bacharel em Zootecnia) - Universidade Federal de Roraima. Boa Vista - RR, 2011.

SAGRILO, E.; VIEIRA, F. J.; NETO, R. B. A.; SOBREIRA, R. S. Criação de galinhas caipiras. ABC da agricultura familiar / Embrapa Informação Tecnológica. Brasília DF. $1^{\text {a }}$ ed. 73 p. n. 20.2007.

SALVADOR, E. L. Qualidade Interna de Ovos de Poedeiras Comerciais Armazenados em Diferentes Temperaturas e Períodos de Estocagem. 2010. 97 f. Dissertação (Mestrado em Zootecnia) - Universidade Federal de Alagoas. Rio Largo - AL, 2011. 